\title{
Building Maintenance Supported on Virtual Reality Environments: Roofs and Walls
}

\author{
Alcínia Zita Sampaio \\ Department of Civil Engineering and Architecture, Technical University of Lisbon (IST/ICIST), Lisbon 1049-001, Portugal
}

\begin{abstract}
The paper presents the description of a research work that has its main objective as the development of a technological tool for supporting building maintenance with resort to new information and visualization technologies. Three main components of the building were analyzed: roof, facades and interior walls. The ceramic tile roof covering constitutes a component of the building envelope and fulfils an important function in its performance, namely in its protection against the permeation of moisture and rain water. Facade coating plays a significant role in the durability of buildings, since it constitutes the exterior layer that ensures wall protection against aggressive actions of physical, chemical or biological nature. The paint coating, applied to interior walls while improving their aesthetic character, performs an important function of protection against deterioration agents related to building use. A survey was conducted of the main anomalies that occur in these components, their respective causes and the adequate interventions, in order to plan maintenance strategies. The collected information serves as a basis for the implementation of applications using interactive visualization technologies to support the planning of building maintenance. During this work, the basic knowledge related to the materials, the techniques of rehabilitation and conservation and the planning of maintenance is outlined and discussed. In addition, methods of interconnecting this knowledge with the virtual applications were explored. The implemented prototypes were tested in real cases. This research work provides an innovative contribution to the field of maintenance, supported by emergent virtual reality technology.
\end{abstract}

Key words: Construction, maintenance, inspections, interaction, virtual reality.

\section{Introduction}

The main aim of a research project PTDC/ECM $67748 / 2006$ [1] concerns the development of virtual models as tools to support decision-making in the planning of construction maintenance. VR (virtual reality) technology can support the management of data throughout the lifecycle of a building, allowing interaction and data visualization. For Kim [2], VR technology is defined as an advanced interface for computer applications, which allows the user to navigate and interact in real time with a computer, generated 3D environments, using multi-sensory devices. Currently, this technology is applied in a vast and diverse number of areas, ranging from medicine to entertainment, to simulators for commercial or

Corresponding author: Alcínia Zita Sampaio, Ph.D., assistant professor, research fields: BIM (building information modeling), maintenance, engineering education and virtual reality. military use, and engineering or architecture areas.

During their service lives, buildings deteriorate and become obsolete. As soon as they are built, the process of decay begins, as well as the deterioration of the fabric and services. The inevitable process of decay can be controlled, and physical life of the building can be extended if they are properly maintained. The degradation of buildings is influenced by several factors, such as the fabric of the material, the environment and the period of usage. If a building is not well maintained, it will affect the user's quality and productivity [3]. So, maintenance has impacted on the efficiency and overall budget of facilities in a building. Today, building maintenance offices are using computer programs toward the control of the maintenance activity. Computer maintenance programs are required for keeping buildings in efficient condition during their lifecycle. They are used as tools to decide upon what, when and 
how much is a maintenance need of a building [4]. According to Therivel [5] and Nita et al. [6], the building maintenance is defined as the diversity of associated activities, as well as the involved interests. The main purpose, on the financial resources use, should be the building preservation. The diagnostic methodology of the deterioration process identifies the defect with the implementation of restrain measures, finding the most important causes, identifying a solution, controlling the outcome and preventing the effects recurrence.

The coating materials can be ceramic tiles in roofs, stones in facades and painted surfaces in interior walls. Factors, such as the constant exposure to the weather, pollutants and the normal actions of housing use, linked to its natural ageing, give rise to its deterioration. So, some irregularities can appear, which can negatively affect the aesthetic aspect and the performance of the element coating [7]. The kind of building material that composes the roofs, facades and the interior wall has a continuous lifestyle, so it requires the study of preventive maintenance (the planning of periodical local inspections) and of corrective maintenance with repair activity analysis. Technical inspections must be drawn by competent assessors to evaluate the physical state of building elements and services and to assess the maintenance needs of the facility. The literature suggests that, ideally, a technical inspection must be performed annually because the longer the period between inspections is, the more accurate and extensive the inspection becomes [8].

A building or its components should perform to the desired level in order to maintain healthy environment. A building's roof covering of ceramic tiles constitutes a component of its surrounding and possesses an important function in the performance of a building, namely in its protection against the permeation of moisture and rain water. The weather significantly influences the state of use of peripheral walls of the building once the humidity through the wall thickness causes anomalies in the inner surface of the wall. According to Flores-Colen and Freitas [8], in normal conditions of habitation use and when correctly applied, a paint coating can remain unaltered for about five years. Since these building components are exposed to bad atmospheric conditions and natural use of the house, the materials frequently show an evident degree of deterioration, requiring maintenance interventions. To perform maintenance activities, a survey of failures in the building must be conducted in order to arrive at the best solution for repair and maintenance. Establishing suitable maintenance strategies for this type of coating is based on the knowledge of the most frequent irregularities, the analysis of the respective causes and the study of the most adequate repair methodologies. Currently, the management of information related to the maintenance of buildings is based on the planning of action to be taken and on the log of completed work. The capacity to visualize the process can be added through the use of $3 \mathrm{D}$ models, which facilitate the interpretation and understanding of target elements of maintenance and, furthermore, the possibility of interaction with the geometric models can be provided through the use of VR technology. The developed VR models can be considered as useful computer tool with advanced visualization capacities in the maintenance field. Westerdahl et al. [9] presented a VR visual model of building showing degradation over time. The VR system in maintenance was found to improve communication between managers and workers and helped to decrease the initial time schedules in repair works.

The VR models of maintenance facilitate the visual and interactive access to results, supporting the definition of inspection reports, whether in new constructions or those needing rehabilitation. The 3D model of the building linked to a database concerning maintenance produces a collaborative virtual environment, that is, one that can be manipulated by partners is interested in consulting, creating, 
transforming and analyzing data in order to obtain results and to make decisions. Namely, inspection reports can be defined and consulted by different collaborators. The process of developing the interface of each application considers these purposes. In addition, these applications can be easily transported to any building place in order to obtain adequate anomaly surveillance and a consequent methodology of rehabilitation, supported on the database. The interaction and the data visualization allowed by the models turn these applications simple and direct to be worked with. The VR applications aimed to promote the use of computerized tools to facilitate and expedite the conduct of inspections. With this tool, the user can perform an inspection that contains all the useful information and also automatically displays the most provable pathologies causes. In addition, the maintenance specialist has access to the history of inspections carried out. So, the rehabilitation expert can do the evaluation of the degradation of the building more effectively and establish an adequate strategy to the repair works.

\section{Interactive Applications}

The implemented prototypes, concerning three building components, roofs [10], facades [11] and interior walls [12], incorporate interactive techniques and input devices to perform visual exploration tasks. To support each system, a database was created which included a bibliographic research support, made in regard to the closure materials used in the roof, and interior and exterior walls of a building, anomalies concerning different kinds of covering material and corrective maintenance. Currently, the study of anomalies is a complex process due to increasing demands by users, development of methods for diagnosis and employed different construction solutions. Thus, the existence of a collection of synthesized and computerized data, enabling the exchange of information between those involved in construction, is an important aid in this process.
Repair activities were also studied. The consulted bibliography concerning diverse material usually applied as building components covering allowed the creating of lists of recommendations and repair methodologies. Based in this research, a database of methodologies was carried out. However, this information intends to present just a suggestion of repair work. The maintenance specialist must evaluate the degree of the anomalies and the real characteristic of the building component covering, in order to establish the most adequate strategy for the irregularity observed in the place. In addition, the database can be updated with new information concerning other irregularities, repair methodologies or even new material. The VR applications intend to be a support tool to the maintenance activity.

The programming skills of those involved in the project had to be enhanced so that they could achieve the integration of the different kinds of databases needed in the creation of the interactive model. The interactive applications support on-site inspections and the on-going analysis of the evolution of the degree of deterioration of the coating materials. A set of computational systems were used in their development and the scheme of links between software is presented in Fig. 1:

- The AutoCAD was used in the creation of the 3D model of the building, based on drawings presented in Fig. 2;

- The VR system, EON Studio, was applied to program the interactive actions linked with the geometric elements of the 3D model (Fig. 3 shows the main interface);

- The Visual Basic software was used in the creation of all the windows of the application and in the establishment of links between components;

- The Microsoft Access application was applied on the definition of a relational database.

\subsection{VR (Virtual Reality) Model of Roofs}

The roof covering is the most effective element of a 
building's surrounding in its edification performance and as such must be efficient in the face of mechanical, thermal, solar radiation and water action [13]. The functional requirements to be fulfilled are essentially defined in terms of habitability, safety, durability and economics. Although several covering materials can

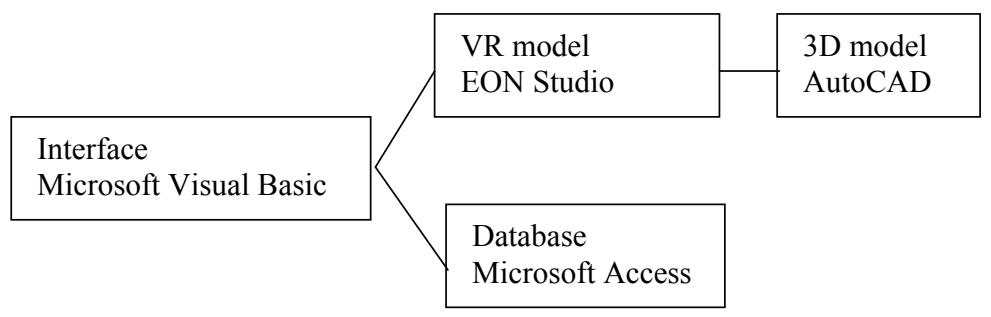

Fig. 1 Scheme of links between software.
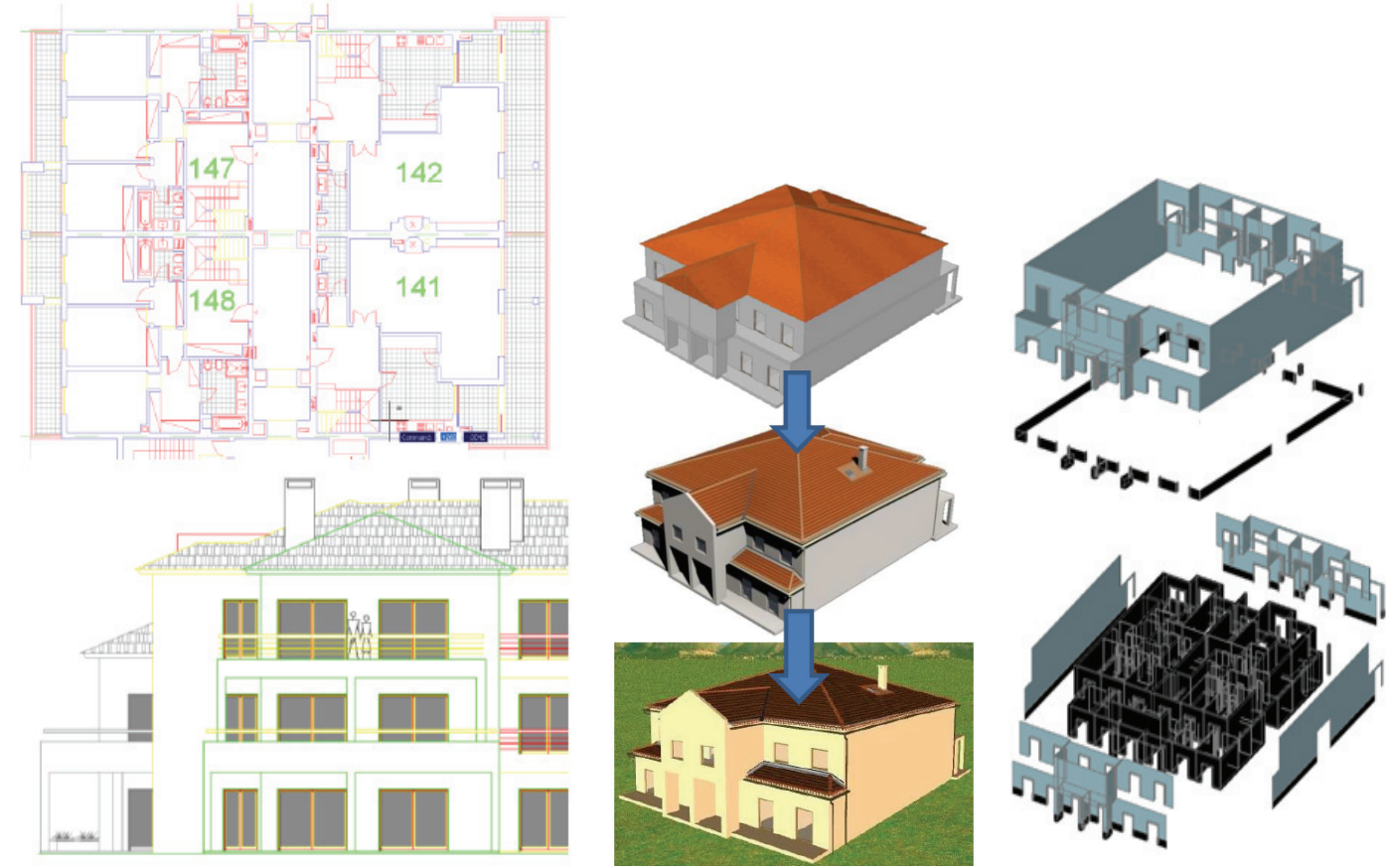

Fig. 2 Technical drawings and the 3D model of the building.

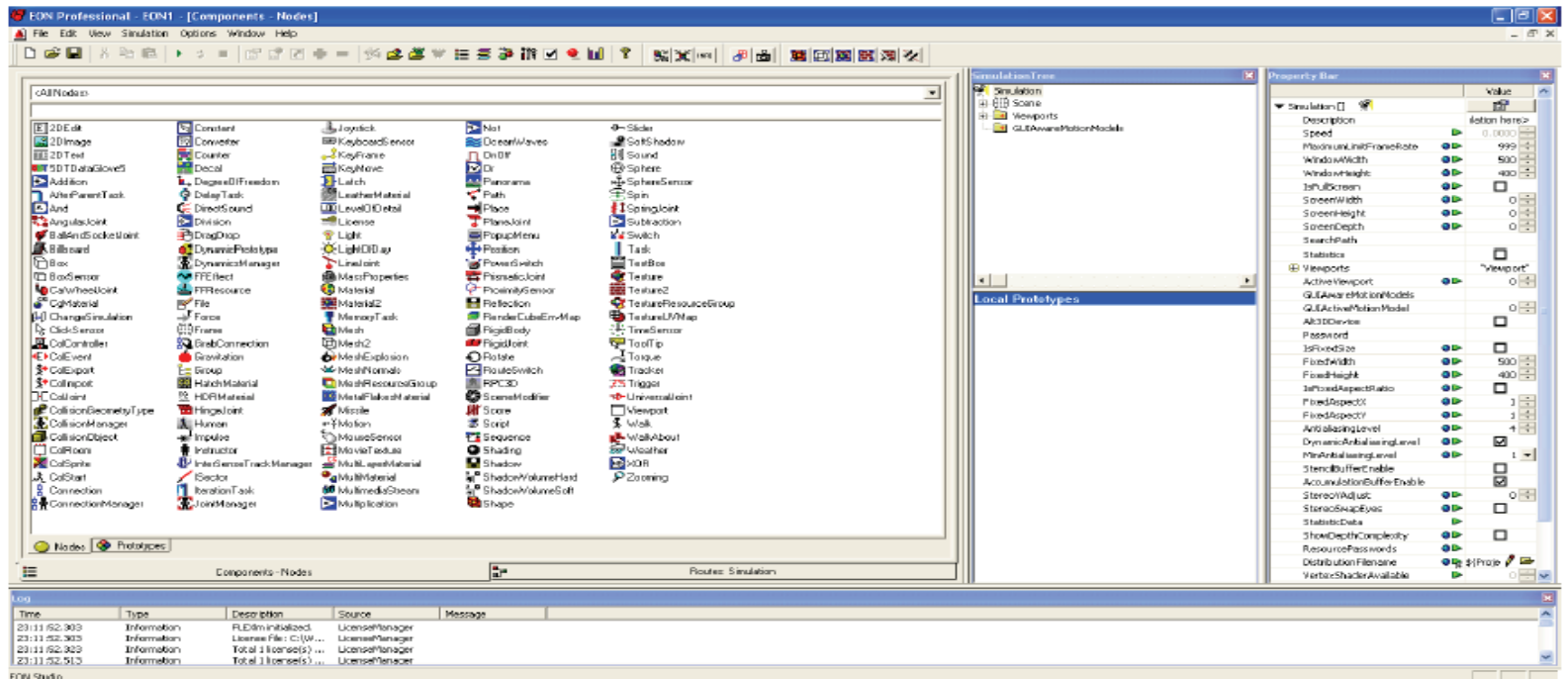

Fig. 3 The EON Studio interface. 
be applied in the execution of pitched roofs, the most frequently applied covering in Portugal is the ceramic tile. The tile covering ensures the continuity of the architectural tradition, allows the creation of visual effects through the variety of shapes and ancillary parts, offers a good performance in the face of atmospheric agents and a high durability and is, furthermore, an ecological product, for it is non-toxic, renewable and biodegradable [14]. As the covering performs a predominant role in the protection of buildings, namely against moisture permeation, it requires a greater attention in regards to the analysis of its deterioration process.

The developed VR application supports the inspection activity [10]. Concerning the pathology analyses and the maintenance planning as a way to optimize the inspection process and the diagnosis of anomalies associated with the roof covering, it was necessary to create a classification system that encapsulated the information collected on this theme. Therefore, four categories on the elements typology were considered:

- the elements that compose the covering support structure;

- the ones that constitute the current surface of the covering;

- the elements considered as singular covering points;

- the ones that form the rainwater draining system.

An in-depth study on the anomalies that might occur and the most likely causes associated with the different elements of the roof are contained within the database. To each anomaly, one or more probable causes in its occurrence are specified, as it is the recommended intervention as a way to eliminate it. To maintain the ease in structuring the database, the causes and the intervention are both linked to the anomaly. Table 1 illustrates two examples of anomalies associated to the type of element (current surface and singular covering points), respective provable causes and recommended interventions. Meetings for all information regarding the described anomalies were prepared tables containing the anomaly, their specifications, as well as the repair solutions and methodologies. This process is then implemented in the program to support the maintenance of buildings. Additionally, a survey of images for each anomaly was conducted.

The implemented interface (Fig. 4) allows the user to perform, intuitively, an inspection to an inclined roof. The first step in using the application is, naturally, to identify the building to be analyzed and the respective roofing characteristics.

Upon opening the selected file, it is possible to manipulate the model through functions that allow the moving of a camera around it and by the selection of covering elements to be identified and monitored. Each element to be monitored must be identified so as to be included in the application's database (Fig. 4). During this process, the camera must be focused on the element so the coordinates of position and orientation to be associated to it are accurate, thus being available for use in subsequent interactions (selection and visualization of an identified element), as shown in Fig. 4.

Table 1 Anomalies associated to respective causes and recommended repair methodology.

\begin{tabular}{|l|l|l|l|}
\hline Element type & Causes & Repair methodology \\
\hline Current surface & $\begin{array}{l}\text { Caying the support structure; } \\
\text { - Lack of walkways on roofs; } \\
\text { - Placing heavy equipment on roof } \\
\text { Singular covering points }\end{array}$ & $\begin{array}{l}\text { Replacement of damage } \\
\text { elements }\end{array}$ & $\begin{array}{l}\text { Element removal and placement } \\
\text { of new trim with higher heights }\end{array}$ \\
\hline
\end{tabular}



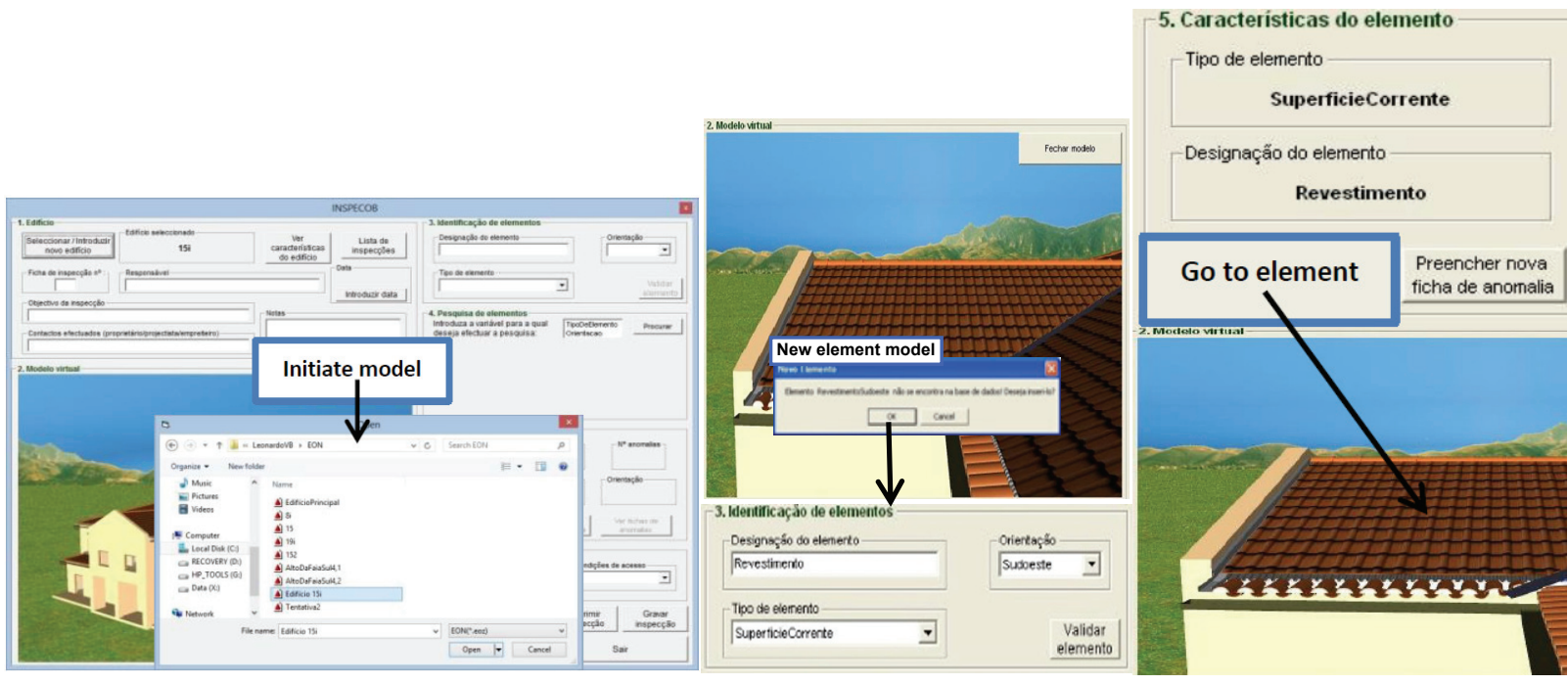

Fig. 4 The VR model of roofs interface.

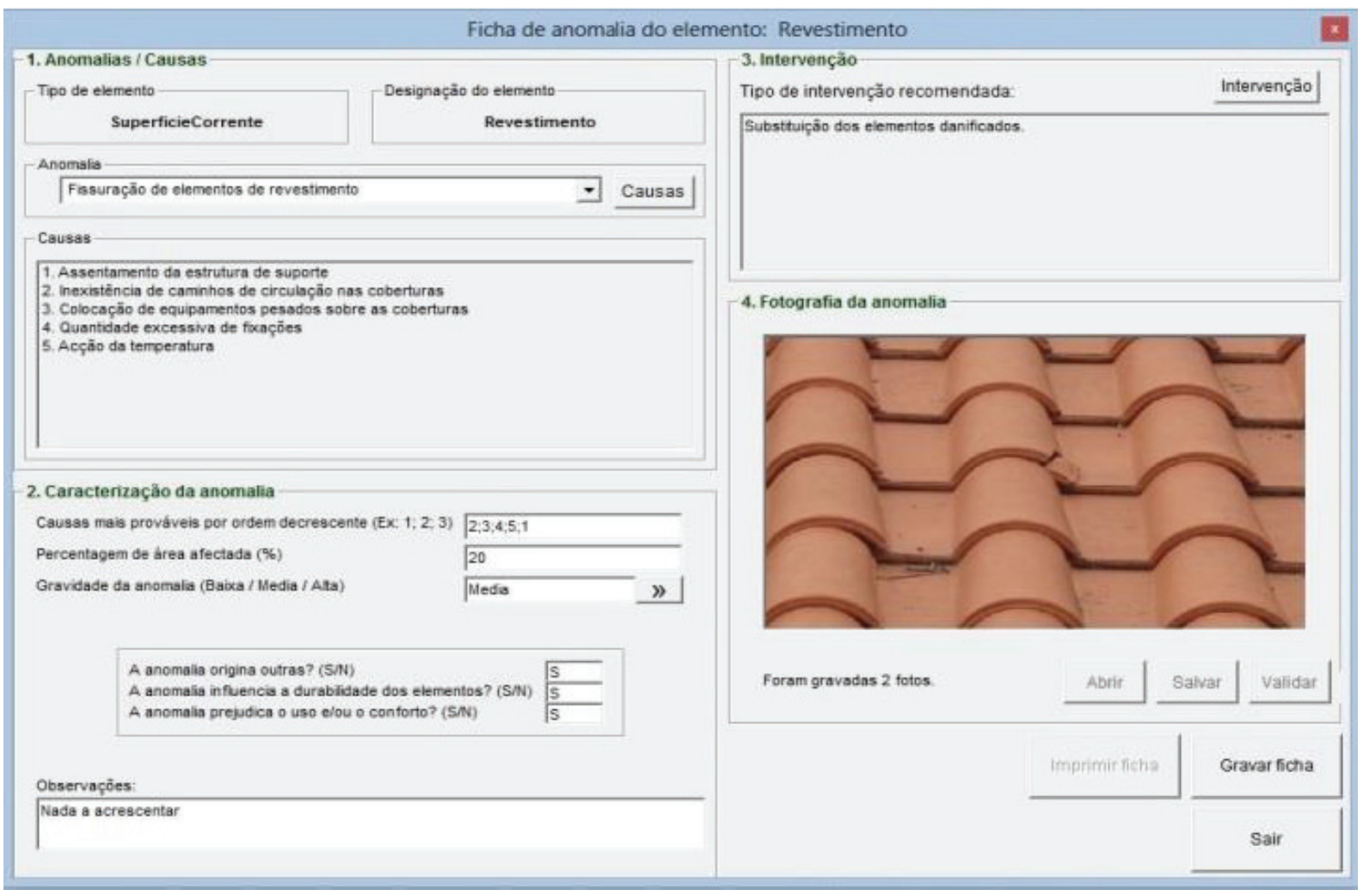

Fig. 5 The anomaly chart interface.

The filling out of a new anomaly chart (Fig. 5) or the viewing of existing charts' data is made available through the interface anomaly chart accessed by the main interface. In the anomaly chart, the scroll-down menu referring to the anomaly field shows the anomalies that have been registered in the database in association with each of the types of elements. So, for example, in relation to the covering element, belonging to the current surface group, the associated anomalies are shown in the scroll-down menu. The causes and intervention modes were equally associated to the anomalies and, therefore, by selecting the respective control buttons, the probable causes and recommended "intervention" fields are 
filled-out with the database records connected to the selected anomaly.

The severity of the anomaly can be characterized according to three parameters (low, medium and high), reflecting the previously realized study. The value shown in this field is then used in the element's color change in the virtual model, through the emission of information to EON, altering itself according to the severity of the anomaly, green for low, yellow for medium and red for high (Fig. 6).

The inspection chart interface also comprises a photo insertion zone, thus it is possible to add photographs taken in the inspection location or other images related to the element being analyzed, forming a considerably relevant complementary information for the subsequent study of repair/maintenance relative to the observed severity.

The user of this application can conduct inspections at any time, access the registered information and the virtual model and, thus, be supported by the historical, define adequate plan for the roof maintenance or reparation work. Such work will only be possible by storing all the information inserted into the application, as well as the changes made to the building's virtual model in a previous inspection allowed by the application. Since the application is based on clear and systematized information, there can be a reduction in inspection subjectivity, and it may be used by different technicians. Thus, the information collected by technicians becomes clear and objective, which permits an easier analysis of the inspection data.

\subsection{VR (Virtual Reality) Model of Facades}

The facades VR model allows interaction with the
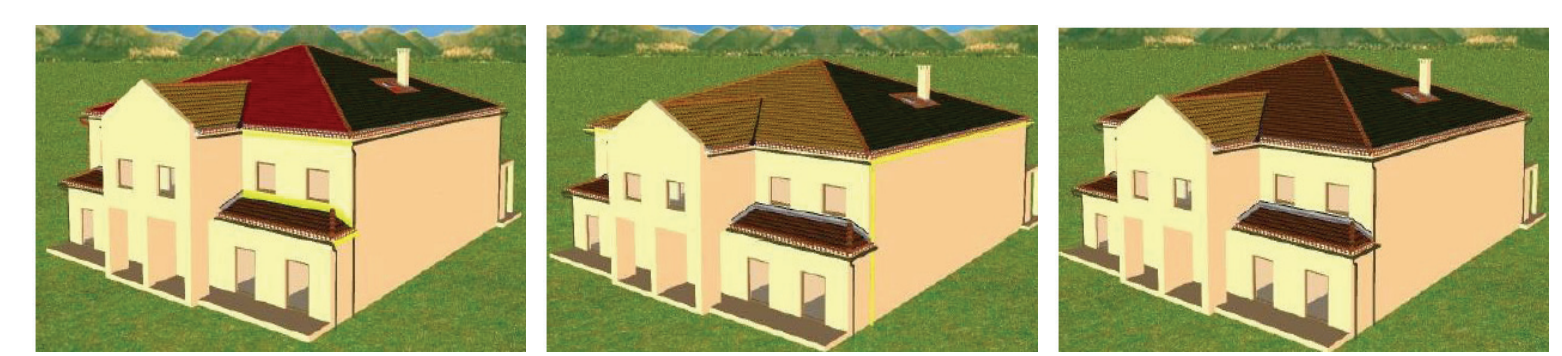

Fig. 6 The color alteration of elements.
3D geometric model of a building, visualizing components for each construction [11]. It is linked to a database (Table 2) of the corresponding technical information concerned with the maintenance of the materials used as exterior closures. The aim of the survey of conditions in facades is to create a database of support software which is meant to be implemented and to support planning of inspections and maintenance strategies in buildings DG449 [7]. The database contains the identification of anomalies that can be observed in different types of finish mentioned above. Each anomaly is called by type of anomaly, which is subdivided into groups designated by the specifications of anomalies. Each specification corresponds to one or more causes of their occurrence. For each specification, there are equated anomaly repair solutions appropriate to their method of repair. The repair techniques included in the database are mainly focused on the treatment of the coating finishing, not considering other layers that make up a facade but often require repair to eliminate all causes.

The visualization of the pathology data of these exterior closure materials requires an understanding of their characteristics [15]:

- types of material, painted surfaces, natural stone panels and ceramic wall tiles;

- application processes, stones (panel, support devices or adherent products), ceramic tiles (fixing mechanism or procedures), painted surfaces (types of paint products, prime and paint scheme surface, exterior emulsion paints or application processes);

- anomalies, dust and dirt, lasting lotus leaf effect,
The color alteration of elements. 
Table 2 Anomalies in facades and associated repair solutions and methodologies.

\begin{tabular}{|l|l|l|l|}
\hline Anomaly & $\begin{array}{l}\text { Specification of } \\
\text { the anomaly }\end{array}$ & Repair solution & Repair methodology \\
\hline $\begin{array}{l}\text { Detachment } \\
\text { Fall in areas with } \\
\text { deterioration of } \\
\text { support }\end{array}$ & $\begin{array}{l}\text { Replacement of the } \\
\text { coat (with use of a } \\
\text { repair stand as } \\
\text { necessary) }\end{array}$ & $\begin{array}{l}\text { (1) Removal of the tiles by cutting grinder with the aid of a } \\
\text { hammer and chisel; } \\
\text { (2) Timely repair of the support in areas where the detachment } \\
\text { includes material constituent with it; } \\
\text { (3) Digitizing layer of settlement; } \\
\text { (4) Re-settlement layer and the tiles }\end{array}$ \\
\hline Cracking/fracturing & $\begin{array}{l}\text { Failure of the } \\
\text { support (wide } \\
\text { cracks with } \\
\text { well-defined } \\
\text { orientation) }\end{array}$ & $\begin{array}{l}\text { Replacement of the } \\
\text { coat (with repair of } \\
\text { cracks in the support) }\end{array}$ & $\begin{array}{l}\text { (1) Removal of the tiles by cutting grinder; } \\
\text { (2) Removal of material adjustment in the environment and } \\
\text { along the joint; } \\
\text { (3) Repair of cracks, clogging with adhesive material (mastic); } \\
\text { (4) Settlement layer made with cement in two layers } \\
\text { interspersed with glass fibre; } \\
\text { (5) Re-settlement layer and the tiles }\end{array}$ \\
\hline
\end{tabular}

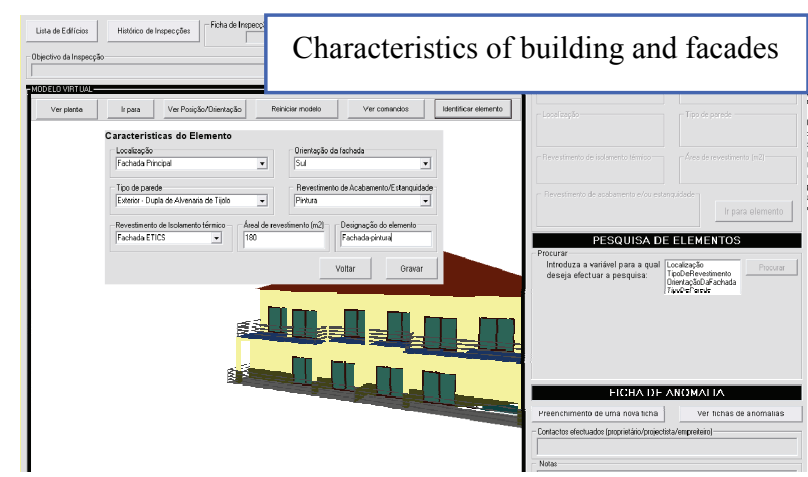

Fig. 7 The main and inspection interfaces of the VR application.

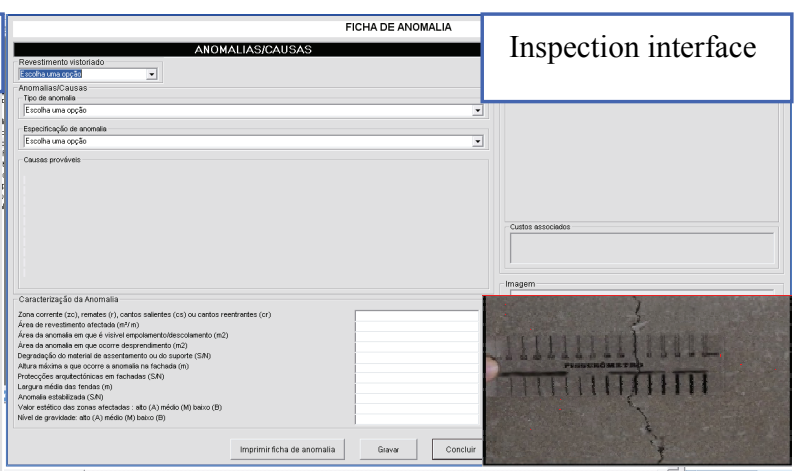

covering power, insufficient resistance to air permeability or weatherproof isolation, damaged stones or ceramic tiles, alkali and smear effect, efflorescence, fractures and fissures;

- repair works, surface cleaning, wire truss reinforcing, cleaning and pointing of stonework joints, removing and replacement of ceramic wall tiles, removing damaged paint and paint surface, preparing and refinishing stone panels.

The VR model interface is composed of a display window allowing users to interact with the virtual model and a set of buttons for inputting data and displaying results (Fig. 7). For each new building to be monitored, the characteristics of the environment (exposure to rain and sea) and the identification of each element of the facades must be defined (facade orientation, double or single exterior wall and area and type of coating).

Once each monitored element has been characterized, several inspection reports can be defined and recorded and thereafter consulted when needed. An inspection sheet (Fig. 7) is accessed by the main interface. Using the drop-down menus of the interface, the user can associate the characteristics of the observed anomaly to a facade element, the type of anomaly, the specification, details and the probable cause of the anomaly, an adequate repair solution and pictures taken in the building. After completing all fields relating to an anomaly, the user can present the report as a PDF (portable document format) file.

The developed software is easy to handle and transport for on-site inspections and comprises information of the causes, solutions and methods for repairing. As the $3 \mathrm{D}$ model is linked to a database in an interactive environment and has a friendly interface to deal with this knowledge, it allows a collaborative system. With this application, the user may fully interact with the program referring to the virtual 
model at any stage of the maintenance process and analyze the best solution for repair work. It can also support the planning of maintenance strategies.

\subsection{VR (Virtual Reality) Model of Painted Walls}

The material most frequently used in the coating of ordinary interior walls of buildings is paint. The durability of the painted coating depends on the environment in which it is used and on the surface it is applied to, as well as the rate of deterioration of the binder in the paint. Irregularities manifest themselves in various ways and in different degrees of severity. According to Coias [16], in normal conditions of exposure and when correctly applied, a paint coating can remain unaltered for about five years. Based on the study made of the causes of the anomalies, specific methodologies for their resolution were

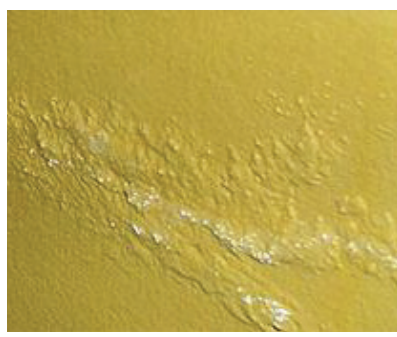

(a)

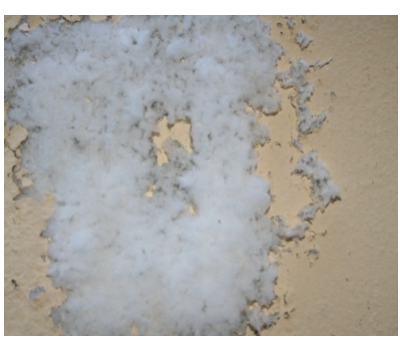

(b)

established.

The developed VR application supports on-site inspections and the on-going analysis of the evolution of the degree of deterioration of the coating [12]. The VR model identifies each interior wall surface in each of the rooms of the house, as independent elements. The application is supported by a database, composed by the most common irregularities (Fig. 8), their probable causes and suitable repair processes, which facilitate the inspection process (Table 3 ).

In addition, the model assigns a color to each of the coating elements and the colors defined by the time variable so that the evolution of the deterioration of the coating material is clearly shown through the alteration in color. The main interface of the application gives access to the inspection and maintenance modules (Fig. 9). On an on-site inspection

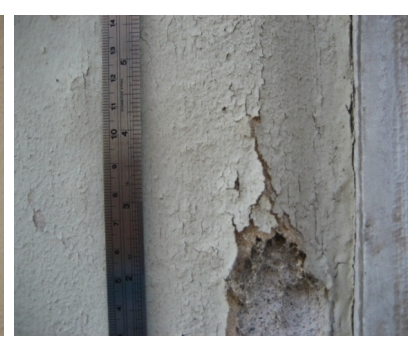

(c)

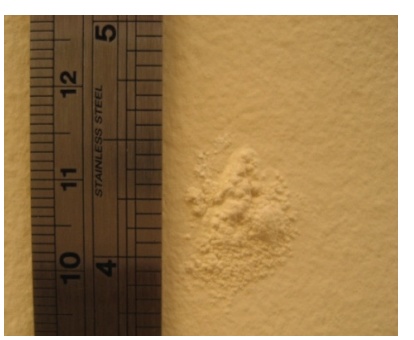

(d)

Fig. 8 Common defects in painted interior walls: (a) swelling; (b) efflorescence; (c) cracking; (d) blistering.

Table 3 Anomalies and associated repair methodology.

\begin{tabular}{|c|c|c|}
\hline Classification & Anomalies & Repair methodology \\
\hline \multirow{6}{*}{ Alteration in colour } & Yellowing & \multirow{6}{*}{$\begin{array}{l}\text { Cleaning the surface and repainting with a finish both compatible with the } \\
\text { existing coat and resistant to the prevailing conditions of exposure in its } \\
\text { environment }\end{array}$} \\
\hline & Bronzing & \\
\hline & Fading & \\
\hline & Spotting & \\
\hline & Loss of gloss & \\
\hline & Loss of hiding power & \\
\hline \multirow{2}{*}{ Deposits } & Dirt pick-up and retention & \multirow{2}{*}{ Cleaning the surface } \\
\hline & Viscosity & \\
\hline \multirow{5}{*}{ Changes in texture } & Efflorescence & \multirow{5}{*}{$\begin{array}{l}\text { - Removal by brushing scraping or washing; } \\
\text { - Repainting the surface; } \\
\text { - When necessary apply sealer before repainting }\end{array}$} \\
\hline & Sweating & \\
\hline & Cracking & \\
\hline & Chalking & \\
\hline & Saponification & \\
\hline \multirow{3}{*}{ Reduction in adhesion } & Peeling & \multirow{3}{*}{$\begin{array}{l}\text { - Proceed by totally or partially removing the coat of paint; } \\
\text { - Check the condition of the base and proceed with its repair where } \\
\text { necessary; } \\
\text { - Prepare the base of the paint work }\end{array}$} \\
\hline & Flaking & \\
\hline & Swelling & \\
\hline
\end{tabular}


visit, the element to be analyzed is selected interactively on the virtual model, and using the inspection interface, the specialist can select the irregularity included in the list of the database, which corresponds to the observed defect, and can select also the probable cause and the prescribed repair methodology (Fig. 9). The inspection data are recorded and associated to each monitored element, allowing subsequently the planning of repair works, thus providing a tool for the definition of a rehabilitation strategy.

The VR application allows the user to monitor the evolution of wear and tear on the paint coating in a house. For this technical information relative to the reference for the paint used, its durability and the date of its most recent application must be added to each element through the maintenance interface (also accessed from the main interface, as shown in Fig. 9).

The period of time between the date indicated to examine the building and the date when the paint was applied is compared to the duration advised for repainting. The value given for this comparison is associated to the RGB (red, green, blue) parameters which define the color used for wall in the virtual model, from pale green (color referring to the date of painting) to red (indicates that the date the model was consulted coincides with that advised for repainting, Fig. 10).

\section{General Procedure and Benefits}

The implemented VR applications support buildings inspections. The geometric models of houses to be inspected are created using geometric modeling systems, based on drawings of the architectural design. Each VR application was implemented to support the inspection of a building component types: roofs, facades and interior walls.

The ability of interaction is added to the geometric models using the selected VR software- the EON Studio. At the inspection building place, the expert must have in his notebook the geometric model inserted in the VR application. On site, the engineer identifies in the model each building component to be monitored. Then, the engineer performs the inspection process by observing the real anomalies. The professional must select the corresponding element in
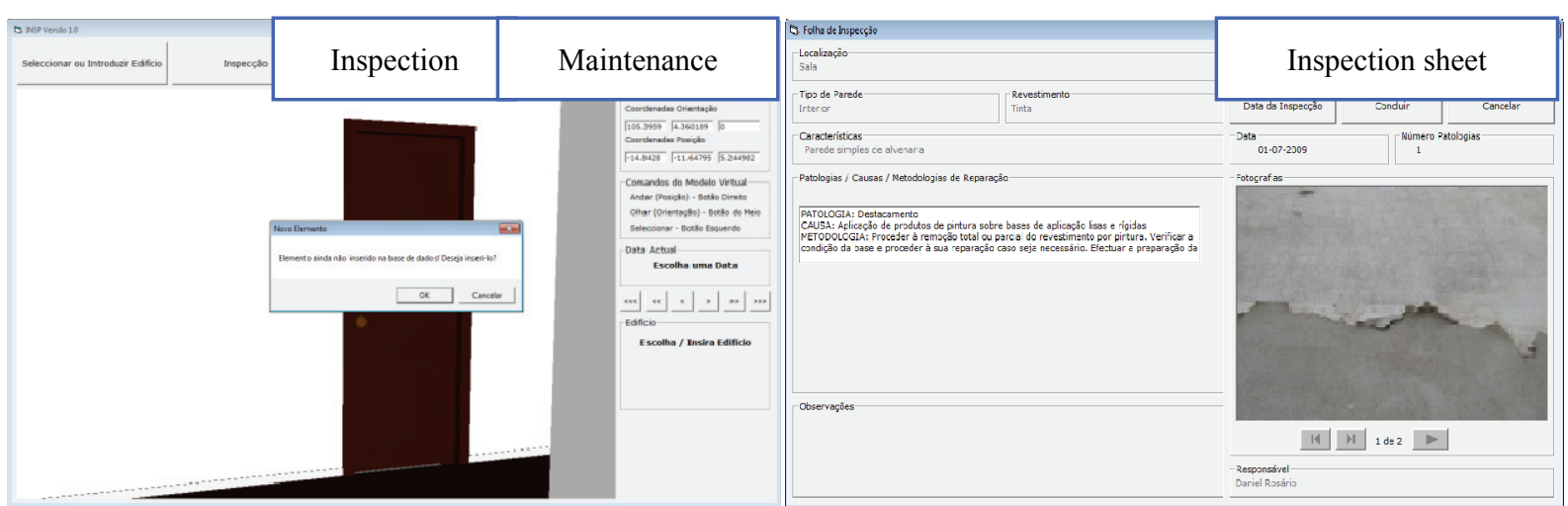

Fig. 9 The main interface of the virtual application and an inspection sheet.
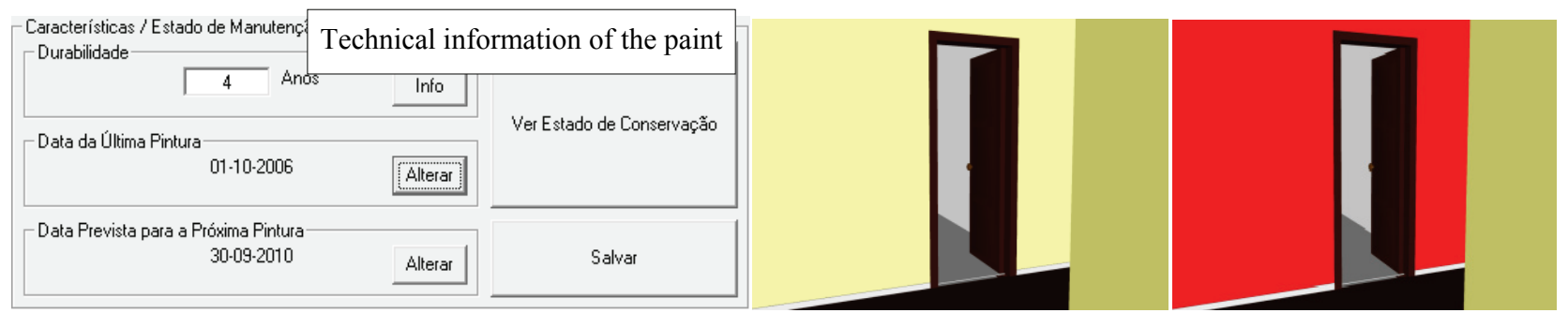

Fig. 10 Coating chromatic alteration according to deterioration state of the paint. 
the model and open an interactive inspection sheet. Based on the observation of the real anomaly, the engineer fills in the set fields of the inspection sheet and adds one or two photos of the observed irregularity. The inspection process should cover all the elements on which the specialist observes an anomaly. Later, the expert examines the set of registered anomalies and establishes a plan of maintenance or repair to the building.

The benefits in use of interactive models which support the buildings inspection, are demonstrated through the facility, as the virtual model of the building can be associated to the irregularities observed on site. And also, after inspection, the engineer can analyze more easily the set of the observed problems and define a global planning with a greater knowledge of the type of anomalies and their extension. The building geometric models, when associated with the result of the inspection, provide a suitable technical communication with the customer or owner of the building.

\section{Conclusions}

The presented VR applications support the inspection activity of roofs, facades and painted interior walls and promote the use of information technology tools with advanced graphic and interactive capabilities, in order to facilitate and expedite the maintenance process. The VR capacity of chromatic alteration was applied in two of the models allowing users to see, in the virtual environment, the state of gravity of anomalies or conservation of the coating materials.

The information about pathologies, causes and repair methods, collected from a specialized bibliography, has been organized in such a way as to establish each model database to be used as a base for the drawing up of a tool to support building maintenance. The main aim of the applications is to facilitate maintenance enabling the rapid and easy identification of irregularities, as well as the possible prediction of their occurrence through the available inspection record. This analysis has been shown as playing an important role in conservation and in the reduction of costs related to the wear and tear of buildings and contributes to the better management of buildings where maintenance is concerned.

With the proposed applications, it is intended that the user at a later stage inspection and assessment of the building may fully interact with the programs, referring to the virtual model at the stage the engineer wants and recreating the best steps to take in the methods of repair by viewing the details of construction and costs and comparing alternatives. The VR software tools are easy to handle and transport to the site inspection comprising information on the causes, solutions and methods for repairing, storing data and information obtained by crossing, including the procedures for inspections and allowing the inspector to view previous inspections both during the inspection and at a later stage of analysis and determination of actions. In this way, the developed tools support maintenance of buildings, using VR interactive technology.

A VR application has some technical limitations regarding the handling of the virtual model. The user must be familiarized with the walking through capacity within a virtual environment. The user must know how to select an element of the model, how to link information and how to consult it. Another limitation concerns the narrow range of components that were studied until now. Other components, like floors, windows and doors, water supply and air conditioning systems, can be also implemented as VR applications for maintenance propose.

\section{Acknowledgments}

The authors gratefully acknowledge the financial support of the Foundation for Science and Technology, a governmental organization for the research project PTDC/ECM 67748/2006 [1]. 


\section{References}

[1] Sampaio, A. Z., and Gomes, A. M. 2011. Virtual Reality Technology Applied as a Support Tool to the Planning of Construction Maintenance. Research Project PTDC/ECM/ 67748/2006, FCT (Foundation for Science and Technology), Lisbon, Portugal.

[2] Kim, J. J. 2011. Virtual Reality. Rijeka: InTech. ISBN 978-953-307-518-1

[3] Korka, J., Oloufa, A., and Thomas, H. 1997. "Facilities Computerized Maintenance Management Systems." $J$. Archit. Eng. 3 (3): 118-23. doi: 10.1061/(ASCE)1076-04 31(1997)3:3(118).

[4] Horner, R. M. W., El'Haram, M. A., and Munns, A. K. 1997. "Building Maintenance Strategy: A New Management Approach." Journal of Quality in Maintenance Engineering 3 (4): 273-80. doi: 10.1108/13 552519710176881.

[5] Therivel, R. 1993. "Systems of Strategic Environmental Assessment." Environmental Impact Assessment Review 13 (3): 145-68. doi: 10.1016/0195-9255(93)90029-B.

[6] Nita, A. K., Sun, M., Petley, G., and Barrett, P. 2002. "Improving the Business Process of Reactive Maintenance Projects.” Facilities 20 (7/8): 251-61. doi: 10.1108/02632770210435161.

[7] Murray, M., Pryke, S., and Yates, T. 2000. Cleaning Exterior Masonry, Part 1 Developing and Implementing a Strategy, Part 2 Methods and Materials. London: BRE (Building Research Establishment) Press.

[8] Flores-Colen, I., and Freitas, V. P. 2008. "Stains in Facades' Rendering-Diagnosis and Maintenance Techniques' Classification." Construction and Building Materials 22 (3): 211-21. doi: 10.1016/j.conbuildmat.200 6.08.023.
[9] Westerdahl, B., Suneson, K., Wernemyr, C., Roupé, M., Johansson, M., and Allwood, C. M. 2006. "Users' Evaluation of a Virtual Reality Architectural Model Compared with the Experience of the Completed Building." Automation in Construction 15 (2): 150-65. doi: 10.1016/j.autcon.2005.02.010.

[10] Afonso, L. P. 2013. "Virtual Reality Technology Applied to the Maintenance of Roofs." M.Sc. thesis, Technical University of Lisbon, Lisbon, Portugal. (in Portuguese)

[11] Gomes, A. R. 2010. "Virtual Reality Technology Applied to the Maintenance of Facades." M.Sc. thesis, Technical University of Lisbon, Lisbon, Portugal. (in Portuguese)

[12] Rosario, D. P. 2011. "Virtual Reality Technology Applied to the Maintenance of Painted Interior Walls." M.Sc. thesis, Technical University of Lisbon, Lisbon, Portugal. (in Portuguese)

[13] Harrison, H. W., Trotman, P. M., and Saunders, G. K. 2009. Roofs and Roofing-Performance, Diagnosis, Maintenance, Repair and the Avoidance of Defects. 3rd ed. London: BRE (Building Research Establishment) Press. Accessed July 14, 2015. http://www.brebookshop.com/samples/139437.pdf.

[14] Garcez, N., Lopes, N., and Silvestre, J. 2012. "System of Inspection, Diagnosis and Repair of External Claddings of Pitched Roofs." Construction and Building Materials 35: 1034-44. doi: 10.1016/j.conbuildmat.2012.06.047.

[15] Gomes, A. M., and Pinto, A. P. 2009. Construction Materials. Didactic Text. Lisbon: IST Student Association, Technical University of Lisbon.

[16] Coias, V. 2009. Inspections and Essays on Rehabilitation of Buildings. 2nd ed. Lisbon: IST Press, 448. ISBN: 978-972-8469-53-5. Accessed July 14, 2015. http://istpress.tecnico.ulisboa.pt/node/285. (in Portuguese) 